\title{
PROPOSTA DE DICIONÁRIO DE SINÔNIMOS PARA LOCUÇÕES ADVERBIAIS E PREPOSITIVAS NA DIREÇÃO PORTUGUÊS-ITALIANO
}

\section{A PROPOSAL FOR A DICTIONARY OF SYNONYMS OF ADVERBIAL AND PREPOSITIONAL PHRASES FROM PORTUGUESE TO ITALIAN}

\author{
Fábio Henrique de Carvalho Bertonha \\ Universidade Estadual Paulista "Júlio de Mesquita Filho", São José do Rio Preto, São Paulo, \\ Brasil \\ Claudia Zavaglia \\ Universidade Estadual Paulista "Júlio de Mesquita Filho", São José do Rio Preto, São Paulo, \\ Brasil
}

Resumo: Este artigo analisa locuções adverbiais e prepositivas compostas por 'a', 'de' e 'em' que contribuíram para a formulação de nosso dicionário especial na direção portuguêsitaliano, da macro à microestrutura. Apoiados em Lyons (1977), Tamba-Mecz (2006) e Regueiro Rodríguez (2013), acreditamos que duas ou mais palavras possam ser consideradas como sinônimas em uma língua se forem intercambiáveis em um dado contexto, sem provocar alteração de sentido, em outro. Visto que assumimos a equivalência entre as línguas como condição sine qua non para a elaboração de dicionários bilíngues, delineamos um verbete-modelo que inclui contextos de uso a fim de atestar a ocorrência das locuções deste estudo. Legitimamos o uso da(s) locução(ões) equivalente(s) por meio de motores de busca na internet. Desse modo, verificamos a correspondência das ocorrências sinonímicas, ou melhor, se os contextos de uso na língua-fonte e na língua-alvo eram os mesmos. Nossos resultados demonstraram a presença de locuções adverbiais e prepositivas bem como a recorrência de advérbios terminados em '-mente' como equivalentes sinonímicos, tanto em português quanto em italiano (ambos, inter- e intralinguisticamente). Com isso, destacamos a importância da sinonímia como fenômeno linguístico, especialmente, para tradutores, pois pode conduzi-los a equivalentes mais apropriados para um contexto particular.

Palavras-chave: Locuções Adverbiais e Prepositivas; Sinonímia; Lexicografia Bilíngue; Dicionário

Abstract: This study analyses adverbial and prepositional phrases composed of 'a', 'de', and
'em', which contributed to the design of our Portuguese-Italian special dictionary, from its
macrostructure to its microstructure. Based on Lyons (1977), Tamba-Mecz (2006), and
Regueiro Rodríguez (2013), we suggest that two or more words can be considered synonyms
in a language if they are interchangeable in a given context, without meaning alteration, in
another. Once we imply that the equivalence between languages is a sine qua non condition
for the elaboration of bilingual dictionaries, we elaborate a prototype entry, which includes
contexts of use in order to certify the occurrence of adverbial and prepositional phrases under
study. We validate the use of the equivalent phrase(s) by means of web search engines. Thus,
we verify the correspondence of synonymic occurrences, or rather, whether the contexts of
use in source and target languages are the same. Our results show the presence of synonymic
equivalents as adverbial and prepositional phrases, as well as the recurrence of adverbs ending
in '-mente' functioning as synonyms, both in Portuguese and Italian (both inter- and intra-
linguistically). For this reason, we highlight the importance of synonymy as a language 
phenomenon, especially for translators, since it can lead them to the most appropriate equivalents in a particular context

Keywords: Adverbial and Prepositional Phrases; Synonymy; Bilingual Lexicography; Dictionary

\section{PRIMEIRAS CONSIDERAÇÕES}

Este artigo é fruto de um levantamento das locuções adverbiais e prepositivas compostas pelas preposições 'a', 'de' e 'em' a partir da macroestrutura do Dicionário Houaiss: sinônimos e antônimos (2011) (doravante, DHSA) com o objetivo de analisar: (i) as locuções sinonímicas e (ii) os exemplos oferecidos na microestrutura do dicionário anteriormente mencionado. A partir desse levantamento, verificamos a possibilidade de se encontrar equivalentes em língua italiana tanto para a palavra-entrada quanto para as locuções definitórias e as frases-exemplo, com base no Dizionario Fraseologico delle Parole Equivalenti Analoghe e Contrarie (2013).

É muito comum que a noção de sinonímia seja entendida, grosso modo, como a troca de um vocábulo por outro desde que haja equivalência semântica. Por vezes, encontramos definições pouco precisas como "sinonímia é o fato de duas ou mais palavras possuírem significados iguais ou semelhantes" (PASCHOALIN; SPADOTO, 1996, p. 347), ou mesmo definições circulares, por exemplo: "sinonímia. s.f. Emprego de sinônimos; qualidade do que é sinonímico" (BUENO, 1996, p. 609). No mínimo, essas são definições que podem levar o consulente a não compreender uma unidade lexical, nem reconhecer sua ocorrência nos discursos, gerando desconhecimento das diferenças dos contextos de uso dos sinônimos.

Entendemos que itens lexicais podem ser tomados como sinônimos em uma mesma língua, e, portanto, podem ser substituídos por outros em um mesmo contexto, desde que mantenham preservado o seu significado. Acreditamos que autores como Lyons (1977), Tamba-Mecz (2006) e Regueiro Rodríguez (2013) nos fundamentam teoricamente nessa linha de pensamento.

Uma vez que trabalhamos também com a língua italiana, não podemos negligenciar os estudos tradutológicos, máxime a questão da equivalência, pois, ao considerarmos sua existência - condição sine qua non para a elaboração de dicionários bilíngues -, devemos estabelecê-la sob as perspectivas de dois campos do conhecimento: (i) Estudos da Tradução e (ii) Lexicografia Bilíngue.

Para esses dois campos é indispensável a noção de equivalência. No entanto, diferentes perspectivas podem comportar variações conceituais; por isso, almejando propor um tratamento lexicográfico (coleta e manuseio de unidades lexicográficas, bem como formulação de verbetes) para alguns tipos de locuções, desejamos refletir sobre os valores atribuídos à equivalência por essas áreas do saber. Com efeito, ao tratarmos da equivalência pelo viés lexicográfico, norteamo-nos por uma abordagem diferente das teorias pós-modernas de tradução, uma vez que defendem perspectivas tradutórias que consideram a realidade extralinguística da língua-alvo, desconstruindo o conceito tradicional de tradução.

Particularmente, avaliamos como dicionários das línguas portuguesa (Brasil) e italiana indicam ou não seu uso, bem como analisamos se ocorrem ou não contextualizações por meio de exemplos que abarquem o item sinônimo proposto na microestrutura do verbete, na medida em que auxiliam um consulente na busca por um sinônimo e otimizam, assim, o trabalho de um tradutor na busca por equivalentes. 


\section{DICIONÁRIO DE SINÔNIMOS E SUAS CARACTERÍSTICAS}

Comumente, um dicionário de sinônimos é monolíngue, recorre a uma distribuição semasiológica das entradas e apresenta caráter sincrônico. Logo, entendemos que cada item da série sinonímica é equivalente ao lema da nomenclatura; por outro lado, a ausência de determinado sinônimo na obra lexicográfica não implica na ausência de determinado significado, mas aponta para o fato de que não tenha sido lematizado, embora já seja lexicalizado. A pretexto de exemplificarmos essa situação, em Houaiss (2009) - doravante HO -, a locução 'em tela' é assim apresentada:

Figura 1: Locução em tela

\begin{tabular}{|l|}
\hline Figura 1: Locução em tela \\
\hline em t. \\
Derivação: por metáfora. \\
em pauta, em discussão \\
\hline
\end{tabular}

Fonte: Houaiss (2009)

Sendo que seu sinônimo 'em pauta' também está lematizado nesse mesmo dicionário, ao passo que, 'em discussão', embora de uso corrente, ${ }^{1}$ não. Na verdade, a sinonímia lexicográfica é apenas uma colocação em perspectiva das possibilidades semânticas de uma unidade lexical, as quais são instanciadas por uma rede de substitutos lexicais.

A nomenclatura de um dicionário de sinônimos é seletiva e limitada, visto que propõe repertoriar apenas um subconjunto do léxico cujas unidades lexicais sejam suscetíveis para estabelecer uma ou mais relações de sentido com significação muito próxima com outras unidades, sendo de tamanho reduzido em relação a um dicionário de língua geral. Já a microestrutura se comporta da mesma forma que a de um dicionário bilíngue, pois a entrada mantém íntima relação com o(s) item(ns) lexical(is) ou sintagma(s) correspondente(s) encontrado(s) em sua(s) acepção(ões), lembrando que suas definições são sinonímicas, diferentemente de um dicionário de língua geral. Concernente ao DHSA a ordenação das acepções e da série sinonímica ocorre mediante ordem alfabética, e não é possível constatar/afirmar que o primeiro sinônimo que figura seja, de fato, o mais frequente.

\section{LOCUÇÕES REPERTORIADAS}

O recorte linguístico feito neste trabalho trata do universo das locuções adverbiais e prepositivas retiradas do DHSA a fim de constituir o repertório da nomenclatura, a saber: 135 locuções (105 adverbiais e 30 prepositivas). Ao delimitarmos o objeto de pesquisa, acreditamos que não só obtemos uma eficácia maior, mas também um ganho de tempo na realização e aprofundamento da pesquisa.

Essa coleta ocorreu por meio de um trabalho perseverante, feito de forma manual, em que as 764 páginas foram analisadas uma a uma, verbete a verbete, percorrendo todas as microestruturas de nossa base de dados (DHSA), cuja duração correspondeu a oito meses de pesquisa em 2016, com o propósito de verificar todas as ocorrências das unidades lexicográficas consideradas "locução" por essa obra dicionarística. Propomos a elaboração de uma obra de referência bilíngue especial e inédita: um dicionário de sinônimos, cuja base textual é composta por locuções adverbiais e prepositivas constituídas pelas preposições ' $a$ ', 'de' e 'em' na direção português-italiano. Considerou-se o levantamento das locuções adverbiais e prepositivas da língua portuguesa do Brasil, constituindo-se o conjunto de entradas (macroestrutura) e a organização lexicográfica (microestrutura, em que constam simultaneamente os respectivos equivalentes em italiano).

${ }^{1} 3.530 .000$ milhões de ocorrência na Web Corpus, em 8 de maio de 2019. 


\section{EQUIVALÊNCIA}

No que tange aos Estudos da Tradução e da Lexicografia Bilíngue, levamos em consideração a relação bastante evidente entre tradutor e dicionário na busca pela equivalência ao constituirmos nossa proposta de obra lexicográfica.

Contraditoriamente, conforme aponta Humblé (2005, p. 233), embora haja uma relação bastante evidente entre tradutor e dicionário, o número de publicações especializadas que elencam elementos desses campos do conhecimento ainda é incipiente.

No que se refere especificamente ao conceito de 'equivalência', percebe-se, de forma bastante genérica, que o termo tem ocupado um lugar de destaque para os campos de conhecimento em estudo, sendo objeto de análises e debates de pesquisadores dessas áreas, sob diversas perspectivas, em diferentes contextos histórico-paradigmáticos. Com base em algumas das visões e entendimentos desses estudiosos, propõe-se olhar para essas concepções e analisar os sentidos que adquire o item lexical, considerando os contextos sociais de produção e recepção nos quais ele está inserido.

Ambos estudos são disciplinas que gozam de autonomia, permitindo-nos que sejam estudadas a partir de princípios próprios. Referindo-se, em particular, ao conceito de "equivalência", percebe-se que se destaca como objeto de análise dessas áreas. Assim, baseado em perspectivas teóricas diversas, discorremos sobre os sentidos que a equivalência adquire, considerando o contexto em que se encontra inserida.

\subsection{A EQUIVALÊNCIA SOB A PERSPECTIVA DOS ESTUDOS DA TRADUÇÃO}

A respeito dos Estudos da Tradução, o conceito de equivalência, de modo mais amplo, fundamenta-se em uma correlação entre um texto de uma língua-fonte e um texto de uma língua-alvo, sendo que o tradutor realiza a tradução almejando a preservação, em alguns momentos, dos traços semânticos neles envolvidos, pois, embora na maior parte das vezes seja semântico, não se pode generalizar para toda e qualquer situação tradutória dado que não apenas o conteúdo, mas também a forma precisa ser levada em consideração. Na busca, às vezes inglória, pela total preservação de sentidos, o tradutor, frente às construções textuais, toma suas decisões para obter êxito no processo tradutório, isto é, faz suas escolhas tradutórias embasado em sua concepção de tradução, que, por consequência, estará atrelada em uma determinada noção de equivalência.

Ao pensarmos sobre equivalência, percebemos que há perspectivas teóricas diferentes que direcionam a ação do tradutor. Pym (2012) ressalta que devemos ser prudentes uma vez que, ao conceito de equivalência na Tradução, podem ser conferidos diversos significados a depender da teoria seguida, os quais podem apresentar pontos dissonantes ou consonantes. Para tanto, o autor argumenta que

\footnotetext{
para identificar esses pontos, é necessário analisar em detalhe os discursos teóricos: as palavras além da história. Assim, damos particular atenção aos termos como 'função', 'norma', 'sistema' e, obviamente, 'equivalência', os quais variam em significado de acordo com o referencial teórico. Apontar para as ditas diferenças constitui um primeiro passo para o diálogo entre paradigmas (PYM, 2012, p. 9). ${ }^{2}$
}

\footnotetext{
2 Tradução nossa para "para poder identificar estos puntos es necesario analizar detalladamente los discursos teóricos: las palabras además de la historia. Así prestamos atención especial a términos como 〈función〉, 〈norma〉, 〈sistema〉 y por supuesto 'equivalencia', todos los cuales varían de sentido según el marco teórico. Apuntar dichas diferencias constituye un primer paso hacia el diálogo entre los paradigmas”.
} 
Já para Menéndez (2012, p. 117), a equivalência deve ser considerada partindo-se de um olhar diacrônico que se principia nos anos 1960 por estudiosos como Jakobson, Catford, Nida, Vinay e Dalbernet - autores que se voltam para o texto original e para a tradução a fim de buscar um paralelismo de valores, nos diversos níveis de linguagem. Nida (1964), por exemplo, acredita que o texto traduzido deva alcançar o nível sociolinguístico e contextual, assim, sua "equivalência dinâmica" pressupunha que a tradução devesse provocar os mesmos resultados de sentido ocorridos nos indivíduos da língua-fonte.

Ainda segundo Menéndez (2012, p. 117), a discussão sobre equivalência percorre a segunda metade do século passado, estimulando o surgimento de outras concepções. Dessa maneira, também na década de 1960, levanta-se a defesa por um tratamento desconstrutivista da tradução, cujo ponto máximo ocorre no fim do século XX e início do XXI. Essa visão pósmoderna, embasada na teoria desconstrutivista, preconiza que não há significados fixos nos textos. Logo, essa visão desconstrói a noção de estabilidade do signo linguístico, desarticulando a relação significante/significado; desse modo, é impossível que qualquer tradução mantenha esse estado de equilíbrio. Assim, o trabalho do tradutor não se restringe apenas a transferir significados, provocando, em grande medida, uma mudança na compreensão do conceito de equivalência (eixo central da concepção tradicional de tradução), mas principalmente a desenvolver uma produção de sentidos a partir de sua leitura do texto da língua-fonte, levando em consideração a realidade contextual da língua-alvo.

A não recuperação biunívoca de sentidos no texto traduzido é defendida por autores pós-modernos como Derrida (1998), Rodrigues (2000), Hurtado Albir (2011), pois, por ser contextual, a equivalência é funcional, relativa, dinâmica, flexível. No entanto, isso não quer dizer que o tradutor seja livre para atribuir qualquer significado sem nenhuma restrição, pelo contrário, é preciso que haja intersecção entre o foco no público-alvo, o contexto sóciohistórico-comunicativo e a interpretação do tradutor a fim de alcançar o sentido almejado.

Diversamente da noção moderna de equivalência, acredita-se que a concepção desconstrutivista da pós-modernidade repensa e ressalta também o papel do tradutor, pois a tradução "não é equivalência, não é complemento, é suplemento: uma significação substitutiva" (RODRIGUES, 2000, p. 209).

Além disso, é preciso refletir sobre as questões envolvidas no processo tradutório, quanto ao fato de que a equivalência interlinguística é o escopo da tradução, pois, no uso de dicionários bilíngues para o auxílio da tradução, tem-se que uma unidade lexical presente nessas obras lexicográficas possa se equivaler em sentido, da língua de partida para a língua de chegada. Sob a perspectiva intralinguística, as palavras-entrada apresentarão, geralmente, na microestrutura do verbete, seus sinônimos com a mesma equivalência de sentido.

Portanto, a sinonímia se afirma como uma relação inter- e intralinguística, contribuindo para o processo tradutório de maneira tal que abrange a Lexicografia Bilíngue (entendendo o léxico como um sistema complexo, assim, estruturando-o sob a forma de dicionários) e a Semântica (pela relação estabelecida entre os signos linguísticos).

Apesar de os enfoques tradicional e pós-moderno se mostrarem divergentes, podemos notar que ambos se debruçam sobre a equivalência ao se verter um texto de uma língua-fonte para uma língua-alvo. É importante destacar ainda que há contraposições tradicionais (biunivocidade, equivalência absoluta, postura estática) e pós-modernas (relação funcional, equivalência relativa, postura dinâmica). ${ }^{3}$

\footnotetext{
${ }^{3}$ Utilizamos "postura dinâmica" apenas para confrontar o enfoque tradicional, por isso não se deve confundir com o conceito de "equivalência dinâmica" discutido e proposto por Nida (1964), pois sustenta que a tradução deveria expressar os mesmos efeitos de seu texto-fonte.
} 


\subsection{A EQUIVALÊNCIA SOB A PERSPECTIVA DA LEXICOGRAFIA BILÍNGUE}

Sob o olhar lexicográfico, toma-se o conceito de equivalência diferentemente dos estudos pós-modernos de tradução, pois, nos dicionários bilíngues, as unidades lexicais tidas como "equivalentes" contemplam de forma parcial a sua correspondente palavra-entrada uma vez que os contextos semânticos não são plena e amplamente contemplados devido à fixidez estabelecida pela Lexicografia Bilíngue. Com efeito, a equivalência se constitui por uma relação determinada entre lexias de sistemas linguísticos distintos que mantêm intersecção contextual de significados.

Apesar de versar sobre as lexias de dois sistemas linguísticos, ressaltamos, conforme afirma Bevilacqua (2006, p. 109), que todo dicionário bilíngue é um texto, por conseguinte, com características e peculiaridades próprias desse tipo de gênero textual. Da mesma maneira como ocorre nos Estudos da Tradução, o conceito de equivalência, cumpre papel central para a Lexicografia Bilíngue.

Fenômenos como a polissemia, mudanças de categoria gramatical ou até mesmo a não existência de um equivalente cultural podem gerar dificuldades para encontrar os correspondentes interlinguísticos. Nessa empreitada, em conformidade com Zavaglia (2016, p. 84), cabe à Lexicografia Bilíngue "procurar dirimir as barreiras interlinguísticas, sendo considerado 'equivalente' um item lexical que contenha a maior quantidade possível de traços semânticos em comum com a unidade lexical de outra língua". Logo, a noção de equivalência entendida aqui vai ao encontro da própria Lexicografia Bilíngue, que é uma disciplina que intervém junto ao papel de obras lexicográficas, que - ao se destinarem ao universo interlinguístico - estimulam a pesquisa por equivalentes, quer sejam propostos a serem confirmados, quer sejam parciais.

Por fim, tanto os conceitos de equivalência para os Estudos da Tradução quanto para a Lexicografia Bilíngue não convivem harmoniosamente, pois o tratamento que lhes é dado difere para cada um desses campos do saber. Aliás, as noções sobre equivalência se ampliam em termos de novas abordagens, não significando que, ao ser adotada por um viés tradutológico ou lexicográfico, implique em um fator de exclusão para o outro campo do saber. De fato, ficará a cargo de cada uma dessas áreas a abordagem a ser realizada da equivalência em seu próprio universo científico, sendo que a própria equivalência apresenta papéis diferentes a depender do tratamento utilizado.

\section{CONSTITUIÇÃO DOS VERBETES DE NOSSO DICIONÁRIO}

A nossa proposta de obra lexicográfica parte de um modelo de verbete-padrão em que o paradigma definicional se constitui de sinônimos que incluem informações de um item sinonímico geral para um específico, seus respectivos equivalentes em italiano e suas contextualizações. Além disso, para cada acepção, existe a barra vertical dupla «\|» como símbolo de separação da sinonímia parcial entre os itens lexicais. Com isso, objetivamos uniformidade nos verbetes, que seguem, portanto, o seguinte padrão:

Figura 2: Modelo de verbete-padrão

ENTRADA (locução adverbial ou prepositiva), em português / equivalente, em italiano

1.Sinônimo em português / equivalente em italiano

[exemplo contextualizado em português] [site/referência/origem]

[exemplo contextualizado em italiano] [site/referência/origem]

Fonte: Os autores. 
Diferentemente de vários modelos de dicionários, propomos facilitar a busca da equivalência tradutória - objetivo principal do consulente -, oferecendo o contexto de uso em ambas as línguas envolvidas.

Quanto à microestrutura, dispusemos todas as informações previstas no planejamento prévio da proposta conferindo homogeneidade e coerência a ela e, a partir disso, seguimos critérios de uniformização, tais como:

a) indicar a locução adverbial ou prepositiva em português, em negrito, a fim de que o consulente se atente à significação nela abarcada, apresentando um tamanho de fonte 12 ;

b) indicar o equivalente em italiano, em «negrito-verde», para que o consulente se atente à significação compreendida na língua-alvo, apresentando um tamanho de fonte 12 ;

c) elaborar as acepções, bem como as séries sinonímicas que correspondem a cada uma delas, em português e com seus respectivos equivalentes em italiano, apresentando um tamanho de fonte 12;

d) contextualizar os equivalentes na língua de partida e na língua de chegada por meio de contextualizações extraídas da Web Corpus, indicando sua origem ao final do contexto e apresentando um tamanho de fonte 9 , fazendo com que as palavras-entrada e seus equivalentes se destaquem, em negrito e sublinhado, a cada novo verbete;

e) inserir barras duplas para separar unidades lexicais sinônimas, mas que não são intercambiáveis em todos os contextos. Conforme características previamente mencionadas, nossos verbetes foram constituídos pelo vocabulário da língua portuguesa (variante brasileira) e pela língua italiana da qual segue a microestrutura elaborada para as unidades lexicográficas propostas.

A organização do dicionário proposto se deu por critérios predefinidos, tais como: ordenação semasiológica e não onomasiológica, por acreditarmos que atenderia melhor o público-alvo, já que o manuseio pode ser mais rápido e, consequentemente, mais eficaz.

Pautamos a nomenclatura a partir do DHSA, contrastando o objeto de estudo com os dicionários de língua geral, HO e Aurélio (Ferreira, 2010), pois acreditamos que, uma vez dicionarizadas e validadas nas três obras, as locuções adverbiais e prepositivas repertoriadas apresentam consagração de uso, servindo-se também como nosso critério e justificativa de escolha. A partir dessa base, buscamos em dicionários bilíngues as locuções equivalentes em italiano para as palavras-entrada e, por conseguinte, para cada um de seus sinônimos.

\section{AMOSTRA DE RESULTADOS ALCANÇADOS}

Referindo-nos às entradas estabelecidas e às acepções sinonímicas, disponibilizamos alguns dados amostrais a fim de demonstrar a ocorrência das locuções e de seus sinônimos.

O verbete proposto 'em triunfo' chama-nos a atenção, sobretudo, pelo fato de apresentar grande quantidade de advérbios de modo terminados em '-mente', não apenas sinônimos em português dessa locução ('pomposamente', 'solenemente'), mas sim várias possibilidades de equivalência interlinguística (fastosamente, grandiosamente, lussuosamente, magnificamente, pomposamente, regalmente, sfarzosamente, solennemente, splendidamente, vistosamente). Um tradutor, tendo à sua disposição uma gama maior de opções tradutórias, pode trabalhar melhor, por exemplo, a questão de registro das unidades lexicográficas (pensando nas marcas diafásicas) ou também o registro de um estrato social específico (pensando nas marcas diastráticas).

Outro exemplo corresponde à palavra-entrada 'a custo' (no DHSA), que possui 
apenas uma acepção, à qual apresentam-se quatro sinônimos ("a duras penas", "arduamente", "dificilmente", "penosamente") que se equivalem. Evidenciamos que essa mesma palavraentrada ("a custo") não figura no $\mathrm{HO}$, ou seja, não se apresenta como entrada, nem mesmo figura em outras microestruturas, fato também estendido a seus advérbios sinonímicos "arduamente" e "penosamente". Já "a duras penas" figura no HO na cabeça de verbete "1 pena", mas não remete à unidade lexical "a custo"; por fim, "dificilmente" se apresenta como uma das entradas da nomenclatura com duas acepções em sua microestrutura, no entanto, sem se remeter a "a custo".

Vale destacar que a escolha pelo uso de um advérbio de modo por um tradutor, tal como "dificilmente" (em português), demonstra que há o interesse em se evidenciar um valor epistêmico (grau de certeza ou de probabilidade em relação a um conteúdo proposicional) a fim de influenciar o interlocutor, interferindo em suas reações, conforme afirma Ribeiro (2003, p. 108-9), quando diz que é uma estratégia de manipular o interlocutor, "uma vez que este entende como um ato de fala dado como certo e seguro".

Nota-se que a escolha feita pelo consulente, no caso um tradutor, por exemplo, por uma ou outra unidade lexical poderá levar a um diferente registro de uso, como para, "em pauta" que possui como sinônimo "em apreço" que carrega uma carga de registro mais formal, ou seja, "em estima", "em consideração", "em admiração", enquanto que seu outro sinônimo, "em questão" - ambos presentes em HO - agrega um sentido mais vulgarizado em termos de "daquilo de que se vem falando". Desse modo, durante o processo tradutório,

pode-se admirar a tradução como exteriorização ou expressão da individualidade criadora do tradutor e, conseqüentemente, estudar a parte do estilo pessoal e da interpretação pessoal do tradutor na forma definitiva da obra. O tradutor é um autor de seu tempo e de sua nação. Pode-se examinar sua poética como exemplo para a diferença na evolução literária de dois povos, para a diferença de poéticas de duas épocas. E finalmente pode-se procurar atrás da obra o método do tradutor como expressão de uma norma de tradução determinada, de uma posição determinada para traduzi-lo (LEVY, 1969, p. 25 apud FURLAN, 1998, p. 5).

Assim, mais uma vez, presenciamos um caso de parassinonímia - "sinônimos em continuum", ou seja, "termos sinônimos são entendidos como aqueles que possuem similaridade significativa, seus significados estão em relação de continuidade" (ZAVAGLIA, 2002, p. 178) - entre os sinônimos "a caminho de" e "prestes a" pertencentes à entrada "em via de"; no entanto, o foco de "a caminho de" está no rumo, na direção do contexto, já "prestes a" se refere à iminência em ocorrer determinado fato, por isso a atenção de um tradutor que se depara diante dessas escolhas precisa permanecer aguçada.

Ao se realizar uma tradução ou versão literária, o tradutor poderia se ver diante da necessidade de uso da locução adverbial "de atalaia" (para o português) ou in agguato (para o italiano); esses são sintagmas que evidenciam um "congelamento" da ação, sendo essa uma ação paradoxalmente estática, porque independe da vontade do indivíduo o tempo em que ficará à mercê de algo; se o tradutor fizer uso de "de atalaia" para um público-alvo infantil, provavelmente, não terá êxito tão esperado quanto se houvesse escolhido como sinônimo "de vigia".

Ao analisarmos o item lexical "menor", identificamos duas locuções que apresentam sentidos muito distintos, pois, enquanto "a menor" representa um valor adverbial em termos de grandeza inferior, "de menor" se refere a um indivíduo que não atingiu a maioridade; desse modo, no primeiro caso, temos um sintagma adverbial e no segundo um sintagma adjetival, expressando sentidos divergentes que não poderiam ser tomados como sinônimos, nem mesmo como parassinônimos, da mesma forma, assim como seus equivalentes italianos. Com isso, um tradutor poderia incorrer em um equívoco hipnótico (SIMÃO, 2016, p. 137) e traduzir, erroneamente, "de menor" por di minore ou di meno, haja vista a existência da lexia, 
conforme atestamos em seguida: "a menor", "de menor”. Esse "efeito hipnótico" já havia sido destacado por Días Fouces (1999), Cintrão (2006) e também retomado por Simão e Stupiello (2017, p. 221) a fim de se refletir a respeito do possível automatismo provocado pela proximidade de línguas.

\section{À GUISA DE CONCLUSÃO}

As locuções são unidades lexicais recorrentes, sobretudo na escrita; assim, as razões que nos impeliram a estudá-las foram as particularidades existentes a essa parte do léxico. E, aqui, esboçamos alguns de nossos resultados alcançados a fim de retomar os principais pontos resultantes de nossa pesquisa contribuindo para o melhor entendimento das locuções, intra- e interlinguisticamente.

Empenhamo-nos para que nossas reflexões, bem como a amostragem do dicionário, estivessem adequadas não apenas a nosso interesse particular, mas também a um interesse sócio-acadêmico, almejando preencher essa lacuna existente em obras bilíngues especiais (português-italiano).

Os casos que apresentamos neste artigo refletem tanto particularidades sinonímicas quanto discussões sobre equivalência no que concerne às locuções adverbiais e prepositivas pesquisadas. A premissa fundamental, segundo a literatura em Lexicologia, a fim de que se instaure a sinonímia, é a coincidência de conceito.

Em suma, este trabalho evidencia que tomar um dicionário nas mãos pode ser uma busca fascinante para um aprendiz do português, do italiano, para um tradutor ou um interessado qualquer quando um consulente se depara com o mundo dos sinônimos e de suas possibilidades de ampliação lexical, tornando o mundo das palavras um potente aliado no processo investigativo para a produção de textos, sejam eles de qualquer natureza.

\section{Referências}

BEVILACQUA, C. R. "Lexicografia bilíngue: aspectos teóricos e reflexões sobre os dicionários bilíngues português-espanhol e espanhol-português". In: ROTTAVA, L.; SANTOS, S. S. (Org.). Ensino e aprendizagem de línguas: língua estrangeira. Ijuí, Brasil: Unijuí, 2006, p. 107-138.

BUENO, F. S. Minidicionário da Língua Portuguesa. São Paulo, Brasil: FTD: LISA, 1996.

CINTRÃO, H. P. Competência tradutória, línguas próximas, interferência: efeitos hipnóticos em tradução direta. TradTerm. v. 12, p. 69-104, 2006. Disponível em: https://www.revistas.usp.br/tradterm/article/view/52262/56297 . Acesso em: 20 fev. 2019.

DERRIDA, J. Carta a um amigo japonês. In: OTTONI, P. (Org.). Tradução: a prática da diferença. Tradução Érica Lima. Campinas, Brasil: Ed. da Unicamp, 1998, p. 19-25.

DÍAZ FOUCES, O. Didáctica de la traducción (portugués-español). 1. ed. Vigo, Espanha: Servicio de Publicación de la Universidad de Vigo, 1999.

FERREIRA, A. B. H. Novo Dicionário Eletrônico Aurélio versão 7.0. 5.ed. Curitiba, Brasil: Editora Positivo Informática LTDA, 2010.

FURLAN, M. Possibilidade(s) de Tradução(ões). Cadernos de Tradução, V. 1, n. 3, p. 89- 
111, jan. $1998 . \quad$ Disponível em: <https://periodicos.ufsc.br/index.php/traducao/article/view/5379/4925> . Acesso em: 20 fev 2019.

HOUAISS, A. Dicionário Eletrônico Houaiss da Língua Portuguesa versão 1.0. Rio de Janeiro, Brasil: Editora Objetiva, 2009.

HUMBLÉ, P. O estudo da tradução e os dicionários. Trabalhos em Linguística Aplicada, v. 44, n. 2, p. 233-246, 2005.

HURTADO ALBIR, A. Traducción y Traductología: Introducción a la Traductología. 5. ed. Madrid, Espanha: Cátedra, 2011.

INSTITUTO ANTÔNIO HOUAISS. Dicionário Houaiss: sinônimos e antônimos. 3. ed. São Paulo, Brasil: Publifolha, 2011.

LYONS, J. Semântica. Tradução de Wanda Ramos. Lisboa, Portugal: Editorial Presença; Martins Fontes, 1977.

MENÉNDEZ, M. N. "El concepto de equivalencia". In: CAGNOLATI, B. et al. (Org.). La traductología: miradas para comprender su complejidad. La Plata, Argentina: Universidad Nacional de La Plata/Facultad de Humanidades y Ciencias de la Educación, p. 114-160, 2012.

NIDA, E. Toward a Science of Translation. Leiden, Holanda: E. J. Brill, 1964.

PASCHOALIN, M. A.; SPADOTO, N. T. Gramática: teoria e exercícios. São Paulo, Brasil: FTD, 1996.

PITTÀnO, G. Dizionario Fraseologico delle Parole Equivalenti Analoghe e Contrarie. 8. ed. Bologna, Italia: Zanichelli, 2013.

PYM, A. Teorías contemporáneas de la traducción: materiales para un curso universitario. Traduire. $\quad$ v. 186, p. 41-49, 2012. Disponível em: http://isg.urv.es/publicity/isg/publications/2011_teorias/pym_teorias_traduccion_web.pdf . Acesso em: 20 fev. 19.

REGUEIRO RODRÍGUEZ, M. L. La sinonimia como recurso de acceso léxico en la enseñanza de lenguas. Revista Nebrija de Lingüística Aplicada. v. 13, p. 965-987, 2013.

RIBEIRO, M. G. C. Uma abordagem semântico-discursiva de estruturas nominais em-mente em interações orais dialogadas. 244f. Tese (Doutorado em Linguística). Universidade Federal de Pernambuco, Recife, Brasil, 2003.

RODRIGUES, C. C. Tradução e diferença. São Paulo, Brasil: Editora UNESP, 2000.

SIMÃO, A. K. G. Sobre a tradução de unidades complexas do léxico. Revista Letras. n. 93 p. 131-151, 2016.

SIMÃO, A. K. G.; STUPIELLO, E. N. Repensando a (in)visibilidade do tradutor de web notícias: propostas para o contexto de formação acadêmica em Tradução. Caracol (USP). n. 14, p. 198-225, 2017. 
TAMBA-MECZ, I. A semântica. São Paulo, Brasil: Parábola, 2006.

ZAVAGLIA, C. Análise da homonímia no português: tratamento semântico com vistas a procedimentos computacionais. 2 v., 360f., v. I; 199f., v. II. Tese (Doutorado em Linguística e Língua Portuguesa). Faculdade de Ciências e Letras, Universidade Estadual Paulista, Araraquara, Brasil, 2002.

ZAVAGLIA, C. "A equivalência na lexicografia bilíngue". In: NADIN, O. L.; ZAVAGLIA, C. (Org.). Estudos do léxico em contextos bilíngues. Campinas, Brasil: Mercado de Letras, 2016, p. 79-95.

Fábio Henrique de Carvalho Bertonha bertonha.tradutor@hotmail.com

Claudia Zavaglia claudia.zavaglia@unesp.br

Recebido em: 28 fev. 2019

Aceito em: 03 maio. 2019

Publicado em: Junho de 2019 